\title{
Corrigendum: Metabolic biotinylation of cell surface receptors for in vivo imaging
}

Bakhos A Tannous, Jan Grimm, Katherine F Perry, John W Chen, Ralph Weissleder \& Xandra O Breakefield

Nat. Methods 3, 391-396 (2006); published online 20 April 2006; corrected after print 10 July 2006.

In the version of this article originally published, reference 12 was incorrect. The correct reference 12 is Querol, M., Chen, J.W., Weissleder, R. \& Bogdanov, A. Jr. DTPA-bis-amide based MR sensor agents for peroxidase imaging. Org. Lett. 17, 1719-1722 (2005). This error has been corrected in the PDF version of the article.

\section{Corrigendum: A highly flexible tRNA acylation method for non-natural polypeptide synthesis}

Hiroshi Murakami, Atsushi Ohta, Hiroshi Ashigai \& Hiroaki Suga

Nat. Methods 3, 357-359 (2006); published online 20 April 2006; corrected after print 10 July 2006.

In the version of this article initially published, the authors did not declare competing financial interests. They have filed a patent covering some of the information described in the paper and now declare competing financial interests. This error has been corrected in the PDF version of the article. 